\title{
Modelling methane emissions from lakes and reservoirs: case study of Lake Kinneret
}

\author{
$\underline{\text { K. Kurucz }}^{\text {a }}$, M.R. Hipsey a and P. Huang a \\ ${ }^{a}$ School of Agriculture \& Environment, University of Western Australia, Perth, 6009, Australia \\ Email: kamilla.kurucz@research.uwa.edu.au
}

\begin{abstract}
Aquatic systems are responsible for 6-16\% of global emissions of methane, a potent greenhouse gas. Methane concentration in the atmosphere is rising continuously, prompting the need for a better understanding of freshwater methane sources and sinks. To date, the global methane budget is based on upscaling emissions from individual lakes resulting in erroneous freshwater methane emission estimates.
\end{abstract}

Methane is produced in the anoxic sediments of lakes and is emitted to the atmosphere via different pathways (Figure 1). These include diffusion, ebullition (bubbling), storage flux and advection through aquatic vegetation, all regulated by different physical, chemical, and biological factors. As a result, methane fluxes significantly vary both within and across systems. Due to its stochastic nature, ebullition is ever challenging to quantify and is generally disregarded from the global methane budget.

To improve methane emission estimates from freshwater, process-based models can be used that enable the simulation of each pathway separately. The aim of this study is to

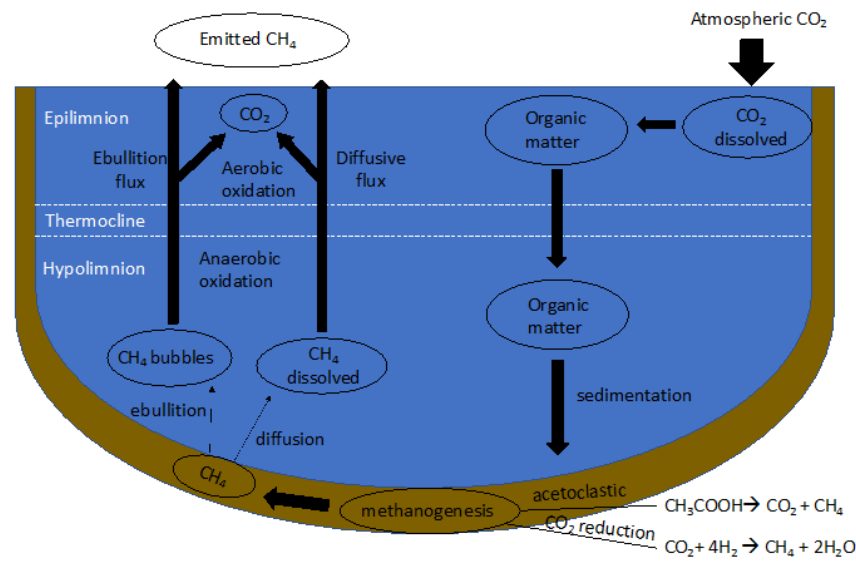

Figure 1. Key processes involved in methane production and methane emission in a stratified lake.

simulate methane emissions from a focus site. This is done through the development of a methane module in the Aquatic Ecodynamics (AED) modelling library which is applied to Lake Kinneret. Whilst Lake Kinneret is a single focus of this study, applying the developed methane model to a site with previously existing monitoring and modelling data will contribute to the building of an open-source general methane model.

In this study, the one-dimensional General Lake Model (GLM) was coupled to the AED modelling library to simulate the thermal dynamics and dissolved oxygen concentration of Lake Kinneret. The methane sources and sinks in the AED carbon module include diffusion, aerobic oxidation, and atmospheric gas exchange. To simulate ebullition, a new algorithm was added to the model. The ebullitive flux in this algorithm varies according to temperature and water level changes. The bubbles released from the sediments either dissolve in the water column or are directly emitted to the atmosphere.

The vertical temperature profile of the lake was successfully reproduced, with a Root Mean Square Error (RMSE) of $1.5^{\circ} \mathrm{C}(\sim 5 \%)$. The model has appropriately resolved the oxygen dynamics, except for the metalimnetic oxygen minimum, with an RMSE of $2.99 \mathrm{mg} / \mathrm{L}(\sim 20 \%)$. The RMSE between the observed and simulated methane concentrations was $56 \mathrm{mmol} / \mathrm{m}^{3}(\sim 10 \%)$. The great annual and within system variations of the methane fluxes are captured well by the model. However, surface methane concentrations are repeatedly overestimated during holomixis. Lastly, the model simulates the seasonality of ebullition well, however, it doesn't capture its stochastic nature reported in the literature.

Process-based models have the ability to account for the variability in lake characteristics and capture the interannual and within system variations in methane emissions. However, to move away from site-specific ebullition models, it is crucial to develop new general ways to parametrise ebullition, enabling its applicability across a gradient of systems.

Keywords: Biogeochemical modelling, freshwater methane emissions, ebullition 


\section{INTRODUCTION}

Methane $\left(\mathrm{CH}_{4}\right)$ is a potent greenhouse gas with a warming potential approximately 25 times greater than $\mathrm{CO}_{2}$ on a molecular basis over a 100-year timescale (McGinnis et al. 2006). Atmospheric methane concentrations have shown an upward trend since 1982 and a sharp increase since 2017; however, the cause of this remains the subject of much uncertainty (Schmid et al. 2017). The methane release of aquatic systems is a significant natural source, contributing 6-16\% to global methane emissions (Bastviken et al. 2014). However, due to the great diversity of lake environments it is difficult to up-scale methane emissions from individual lakes and adequately account for them in the global methane budget.

Methane is the primary end product of organic matter decomposition in lakes. The main regulators of anoxic methane production are oxygen concentration, the availability of recently produced organic matter, temperature and alternative electron acceptors. High oxygen concentrations in sediments inhibit methane production (Borrel et al. 2011). Methanogenesis has been shown to increase with temperature and the availability of fresh organic matter, however, alternative electron acceptors, namely $\mathrm{SO}_{4}^{2-}, \mathrm{Fe}^{3+}, \mathrm{NO}_{2}^{-}, \mathrm{NO}_{3}^{-}, \mathrm{Mn}^{4+}$ can outcompete methanogens for uptake of $\mathrm{H}_{2}$ and acetate, limiting methanogenesis (Borrel et al. 2011).

In lakes and reservoirs, different methane pathways include ebullition (bubbling), diffusion, storage flux and advection through aquatic vegetation (Bastviken et al. 2004). It is challenging to accurately estimate aquatic methane emissions as different emission pathways are regulated by different environmental controls, including physical, chemical, and biological factors. This results in great variability between methane fluxes both within and across systems. In general, freshwater methane emissions are regulated by the rate of methane production and show great interannual and seasonal variations (Bastviken et al. 2004). The diffusive flux transports dissolved methane to the water-air interface where it is exchanged with the atmosphere according to the concentration gradient. Lake thermal stratification limits the diffusive flux and accumulates dissolved methane in the anoxic hypolimnion which can be emitted as a result of lake overturn (storage flux). Aerobic and anaerobic oxidation are sinks for dissolved methane and prevent methane reaching the water level surface, especially in deep stratified lakes. Methane can be oxidized in the water column, the sediment-water interface or in the sediments, potentially reducing methane emissions to the atmosphere.

Ebullition significantly contributes to methane emissions from lakes, however, it is difficult to quantify due to its stochastic nature over space and time (Sanches et al. 2019). Methane has low water solubility, hence high methane concentrations in anoxic sediments lead to the production of bubbles, which are subsequently emitted to the atmosphere (Schmid et al. 2017). Ebullition is highly temperature dependent and sudden changes in water level and air pressure can result in abrupt ejections of methane bubbles from the sediments when bubbles overcome the sediment tension holding them in place (DelSontro et al. 2010). Ebullition predominantly bypasses oxidation, however, despite its evident contribution to freshwater methane emissions it is poorly accounted for in the global methane budget.

Due to significant variations between pathways, process-based models can be used to estimate each flux component separately and improve methane emission estimates. Current methane models include simulating methane production, diffusion and ebullition in arctic lakes, permafrost lakes and a deep subtropical lake (i.e. Stepanenko et al. 2016). The application of these models however, is limited to the site and therefore cannot be applied across a diversity of lake systems. Conversely, there is a need for a general methane model that can resolve the high variability of methane generation, attenuation and emission and can be applied across a wide range of lake systems.

The aim of this study is to simulate methane emissions from a focus site. This is done through the development of a methane module in the AED modelling library (Hipsey et al. 2013), which is applied to Lake Kinneret (Israel), a system that has been monitored extensively. Whilst Lake Kinneret is the single focus of this study, the calibrated model is intended to be used to predict methane emissions from other freshwater lakes. Ultimately, it is envisaged that improved use of the model to predict methane emissions from a diversity of lakes will reduce uncertainties within the global methane budget.

\section{MODELLING APPROACH}

\subsection{Study site}

Lake Kinneret is a deep monomictic lake located in the Afro-Syrian Rift Valley in Israel. The maximum depth of Lake Kinneret is approximately $44 \mathrm{~m}$ with a surface area of $167 \mathrm{~km}^{2}$ (Schmid et al. 2017). Lake Kinneret is generally thermally stratified between April and December. Anoxic conditions in the hypolimnion start to develop in May, dominating the entire stratified period. 


\subsection{Data}

Details on the weather, inflow, outflow and temperature data can be found in Gal et al. (2003) and dissolved oxygen data in Schmid et al. (2017). Data consisting of dissolved methane concentrations in Lake Kinneret was extracted from Schmid et al. (2017), using WebPlotDigitizer (http://arohatgi.info/WebPlotDigitizer), a web-based tool to obtain high-precision numerical data from plots.

\subsection{Hydrodynamic model}

GLM is one-dimensional open-source code designed to simulate the hydrodynamics of a diverse range of lake types from all climatic regions (Hipsey et al. 2019). GLM simulates the vertical temperature distribution, the water, ice and heat balance and the transport and mixing in the lake. It was used to simulate the thermal dynamics of Lake Kinneret.

\subsection{Biogeochemical model}

The AED modelling library is an open-source project which includes the development of an aquatic ecology model (Hipsey et al. 2013). It consists of different modules such as dissolved oxygen (DO), tracers, suspended solids \& retention time, inorganic nutrients: $\mathrm{C} / \mathrm{N} / \mathrm{P} / \mathrm{Si}$, organic matter: DOM/POM, phytoplankton and zooplankton. These modules can be coupled to hydrodynamic models like GLM to simulate the water quality and ecosystem dynamics of the lake. To simulate the DO concentration in Lake Kinneret, the AED oxygen module was used. In the module, DO concentration changes over time according to the mass balance of atmospheric exchange, sediment oxygen demand, the use of DO by microbes during organic matter mineralisation and nitrification, oxygen production during photosynthesis, oxygen consumption during respiration and oxygen consumption and respiration by other optional biotic components that suits the lake in focus. The carbon module includes the methane diffusive flux, aerobic methane oxidation and the air-water exchange of dissolved methane and was used to simulate methane dynamics. As it is a significant pathway, ebullition was added to the model using the approach by Schmid et al., 2017.

\subsection{Methane model overview}

By identifying the methane sources and sinks, the methane concentration in the water column can be determined, expressed as follows:

$$
\frac{d C H_{4}}{d t}=f_{\text {sed }}^{\mathrm{CH}_{4}}-f_{\text {ox }}^{\mathrm{CH}_{4}} \pm f_{\text {atm }}^{\mathrm{CH}_{4}}+f_{\text {dis }}^{\mathrm{CH}_{4-b u b}}
$$

where $f_{\text {sed }}^{\mathrm{CH}_{4}}$ is the sediment diffusive flux, $f_{o x}^{\mathrm{CH}_{4}}$ is the rate of $\mathrm{CH}_{4}$ oxidation, and $f_{\text {atm }}^{\mathrm{CH}_{4}}$ is the air-water exchange of dissolved methane. Bubbles moving through the water column after release from the sediments can also dissolve, $f_{d i s}^{\mathrm{CH}_{4-b u b}}$.

\section{Sediment diffusive flux}

The sediment diffusive flux is primarily controlled by temperature and oxygen availability. Due to its effect on gas solubility and organic matter decay rate, increasing temperatures enhance the diffusive flux (DelSontro et al. 2010). However, as oxygen concentrations increase, methane is oxidized, diminishing the diffusive flux. This is formulated as follows:

$$
f_{\text {sed }}^{C H 4}=F_{\text {sed }}^{C H 4} \theta_{\text {sedch } 4}^{T-20} \Phi_{O 2}^{c h 4}\left[O_{2}\right] \frac{1}{\Delta z}
$$

where $F_{\text {sed }}^{C H 4}$ is the diffusive flux from the sediments, $\theta_{\text {sedch } 4}^{T-20}$ is the temperature multiplier of the sediment diffusive flux, $\Phi_{O 2}^{c h 4}\left[\mathrm{O}_{2}\right]$ is the oxygen mediation of the sediment diffusive flux (3) and $\Delta z$ is the vertical thickness of the computational layer. The oxygen mediation of the sediment diffusive flux is expressed as:

$$
\Phi_{O 2}^{\mathrm{Ch} 4}\left[\mathrm{O}_{2}\right]=\frac{K_{\mathrm{CH} 4-\mathrm{O} 2}}{\mathrm{CO}_{\mathrm{O} 2}+K_{\mathrm{CH} 4-\mathrm{O} 2}}
$$

where $C_{\mathrm{O} 2}$ is the concentration of oxygen and $K_{\mathrm{CH} 4-\mathrm{O} 2}$ is the half saturation oxygen concentration controlling the flux.

\section{Oxidation rate}

Aerobic oxidation is mediated by methanotrophs and is the most significant sink for dissolved methane released from lake sediments. The metabolic rate of methanotrophs increases with increasing temperatures. This process can be described according to Michealis-Menten Kinetics as follows:

$$
f_{o x}^{\mathrm{CH}_{4}}=R_{\text {oxmax }}^{\mathrm{CH}_{4}} \Phi_{O 2}^{\mathrm{ch} 4-o x}\left[\mathrm{O}_{2}\right] \theta_{\text {ox }}^{\mathrm{T-20}}\left[\mathrm{CH}_{4}\right]
$$


where $R_{\text {oxmax }}^{\mathrm{CH}_{4}}$ is the maximum reaction rate of methane oxidation at $20^{\circ} \mathrm{C}, \Phi_{O 2}^{c h 4-o x}\left[\mathrm{O}_{2}\right]$ is the oxygen mediation of the oxidation rate (5) and $\theta_{o x}^{T-20}\left[\mathrm{CH}_{4}\right]$ is the temperature multiplier for methane oxidation. The oxygen mediation of the oxidation rate is expressed as follows:

$$
\Phi_{O 2}^{c h 4-o x}\left[O_{2}\right]=\frac{C_{O 2}}{C_{O 2}+K_{C H 4-O 2}}
$$

\section{Air-water exchange}

Dissolved methane transfer occurs across the air-water interface based on the gas solubility, the amount of turbulence at the interface and the concentration gradient between the air and water, using the widely used approach introduced by Wanninkhof (1992):

$$
f_{\text {atm }}^{\mathrm{CH}_{4}}=k_{600}^{\mathrm{CH} 4} \mathrm{~K}_{0-\mathrm{CH} 4}\left(\mathrm{pCH}_{4}^{w}-p \mathrm{CH}_{4}^{a}\right)
$$

where $k_{600}^{C H 4}$ is the air-water gas transfer velocity for $\mathrm{CH}_{4}, K_{0-C H 4}$ is the solubility of $\mathrm{CH}_{4}, p C H_{4}^{w}$ and $p C H_{4}^{a}$ are the $\mathrm{CH}_{4}$ concentrations in the water surface and the air, respectively. The gas transfer velocity can be calculated using various methods, in this study, the formula by Wanninkhof (1992) was adopted:

$$
k_{600}^{C H 4}=0.31 U^{2}\left(\frac{S c}{660}\right)^{-\frac{1}{2}}
$$

where $\mathrm{U}$ is the wind speed and $\mathrm{Sc}$ is the Schmidt number.

\section{Ebullition}

Methane bubbles are formed when anoxic methane production in the sediments exceeds the rate of oxidation and diffusion. As the bubbles overcome sediment tension, they are released to the water column. The sediment ebullitive flux is greatly depth-dependent and is enhanced by increasing temperatures (DelSontro et al. 2010). Moreover, it has been observed that falling water levels and decreasing hydrostatic pressure also result in increased ebullitive flux rates. The ebullitive flux is formulated mathematically as follows:

$$
f_{\text {sed }}^{C H_{4-b u b}}=F_{\text {sed }}^{C H_{4-b u b}} \theta_{\text {sedCH }}^{T-20}{ }_{4-b u b} \Phi_{\Delta \mathrm{z}}^{C H_{4-b u b}}[\Delta \mathrm{z}] \frac{1}{\Delta \mathrm{z}}
$$

where $F_{\text {sed }}^{C H_{4-b u b}}$ is the sediment ebullitive flux, $\theta_{\text {sedCH }}^{T-20}{ }_{4-b u b}$ is the temperature multiplier and $\Phi_{\Delta \mathrm{z}}^{C H_{4-b u b}}[\Delta \mathrm{z}]$ accounts for the effect of water level fluctuations on the sediment ebullitive flux. By adopting a site-specific regression equation derived by Ostrovsky et al. (2013), $\Phi_{\Delta \mathrm{z}}^{C \mathrm{CH}_{4-b u b}}[\Delta \mathrm{z}]$ is calculated as follows:

$$
\Phi_{\Delta \mathrm{z}}^{C H_{4-b u b}}[\Delta z]=c_{n} \exp \left\{k_{r e g}(\bar{z}-z)\right\}
$$

where $c_{n}$ is a normalizing constant, $k_{r e g}$ is the exponential factor from the regression equation, $\bar{z}$ and $z$ are the average and current water depths respectively. To account for the spatial variability of ebullition, the lake was partitioned into ten sediment zones and different ebullitive flux rates were assigned to each zone. The zonespecific ebullitive fluxes were calculated by multiplying the total ebullitive flux by the probability of bubble release for each zone, presented by Schmid et al., 2017. The methane bubbles released from the sediments either dissolve in the water column or are directly emitted to the atmosphere. In Lake Kinneret, it was found that $\sim 7 \%$ of the bubbles dissolve in the water column below $20 \mathrm{~m}$, in the hypolimnion, and $\sim 33 \%$ of the bubbles dissolve in the water column above $20 \mathrm{~m}$, in the epilimnion (Schmid et al. 2017). This was formulated by implementing a depth-dependent dissolution rate $k_{\text {diss }}[z]$ :

$$
f_{\text {dis }}^{C H_{4-b u b}}=k_{\text {diss }}[z] f_{\text {sed }}^{\mathrm{CH}_{4-b u b}}
$$

The remaining $\sim 60 \%$ of methane bubbles released from the sediments are directly emitted to the atmosphere.

\subsection{Model setup and simulation}

The methane sources and sinks, including the sediment diffusive flux, the sediment ebullitive flux, methane oxidation, dissolution of methane bubbles, gas exchange at the water-air interface and the atmospheric ebullitive flux were simulated from 01/01/1998 until 23/02/2002. To allow for the implementation of depthdependent sediment diffusive and ebullitive fluxes, ten sediment zones were set up.

\subsection{Model calibration}

The simulated temperature, DO and dissolved methane concentrations were calibrated utilizing the field data, implementing the Covariance Matrix Adaptation Evolution Strategy (CMA-ES) optimization method. 


\section{RESULTS}

\subsection{Temperature}

The simulated and observed temperatures at different depths are presented in Figure 2. The vertical temperature profile of the lake was successfully reproduced by the calibrated model. The simulated temperatures were comparable to the observed temperatures with an RMSE of $1.5{ }^{\circ} \mathrm{C}(\sim 5 \%)$ in the whole water column. It appears that the model captured the onset and end of seasonal thermal stratification well. The peak of the epilimnion temperatures in the stratified period was slightly overestimated in each simulated year. Temperatures in the hypolimnion were marginally underestimated.

\subsection{Dissolved oxygen}

The simulated and observed DO concentrations at different depths are presented in Figure 3. The calibrated model has appropriately resolved the DO dynamics in the water column, except for the metalimnetic oxygen minimum, which remains a major challenge in Limnology. It seems that the model captured the trend in DO concentrations in the epilimnion but compared to the observed values, there is a lag in the simulated peak DO concentrations. The RMSE of DO concentrations in the water column was $2.99 \mathrm{mg} / \mathrm{L}(\sim 20 \%)$. DO concentrations in lakes are controlled by numerous complex processes hence a $20 \%$ error is acceptable and appropriate for the purposes of this study.

\subsection{Dissolved methane}

The simulated and observed dissolved methane concentrations at different depths are presented in Figure 4. The RMSE between the observed and simulated values was $56 \mathrm{mmol} / \mathrm{m}^{3}$ $(\sim 10 \%)$. The simulated methane concentrations in the epilimnion were overestimated during holomixis each year. The simulated dissolved methane concentrations in the hypolimnion captured the observed patterns well. However, it seems that small under and overestimations occur each year.

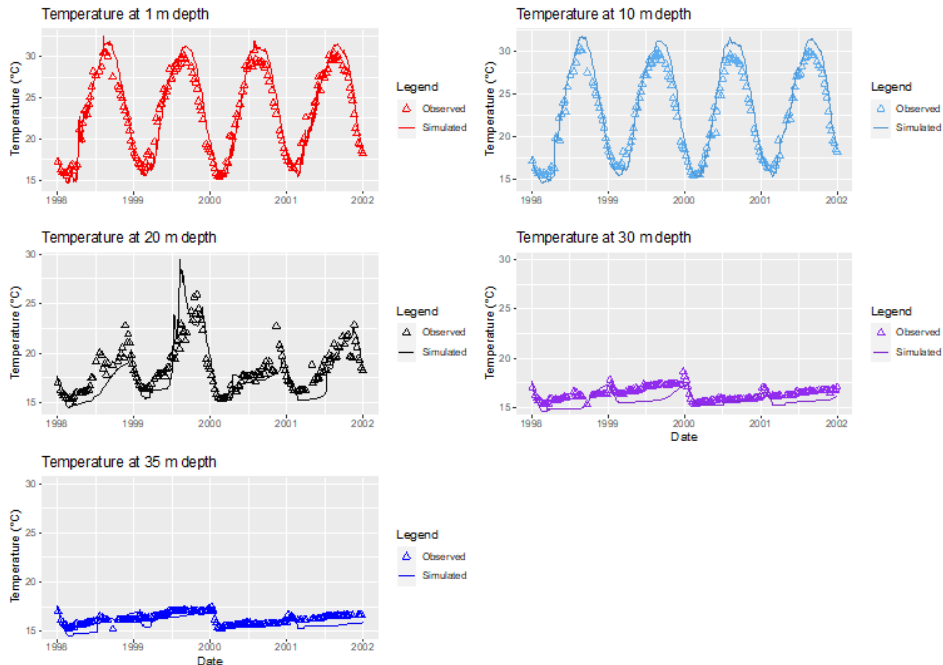

Figure 2. The observed vs. simulated temperatures at $1 \mathrm{~m}, 10 \mathrm{~m}$, $20 \mathrm{~m}, 30 \mathrm{~m}$ and $35 \mathrm{~m}$ depths.
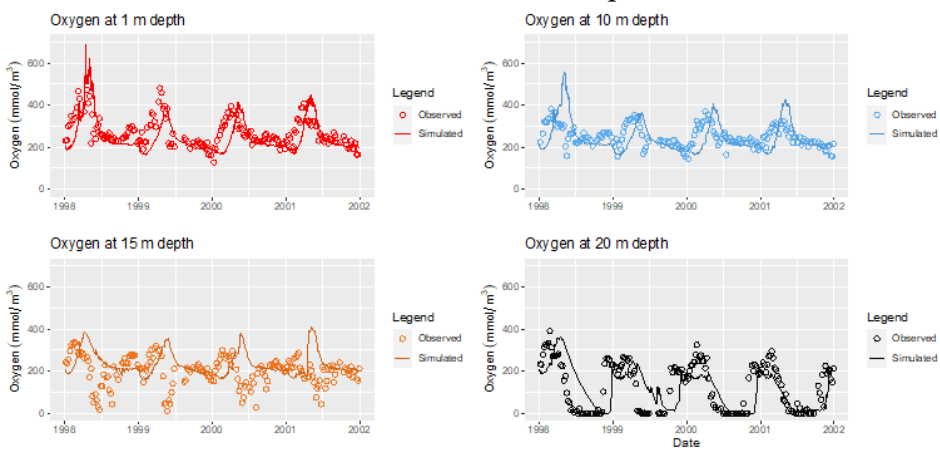

Oxygen at $30 \mathrm{~m}$ depth

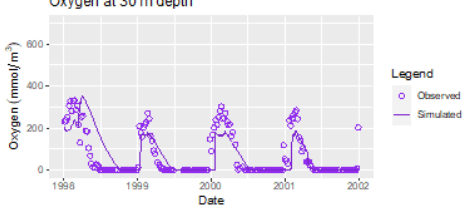

Figure 3. The observed vs. simulated DO concentrations at $1 \mathrm{~m}, 10$ $\mathrm{m}, 15 \mathrm{~m}, 20 \mathrm{~m}$ and $30 \mathrm{~m}$ depths.
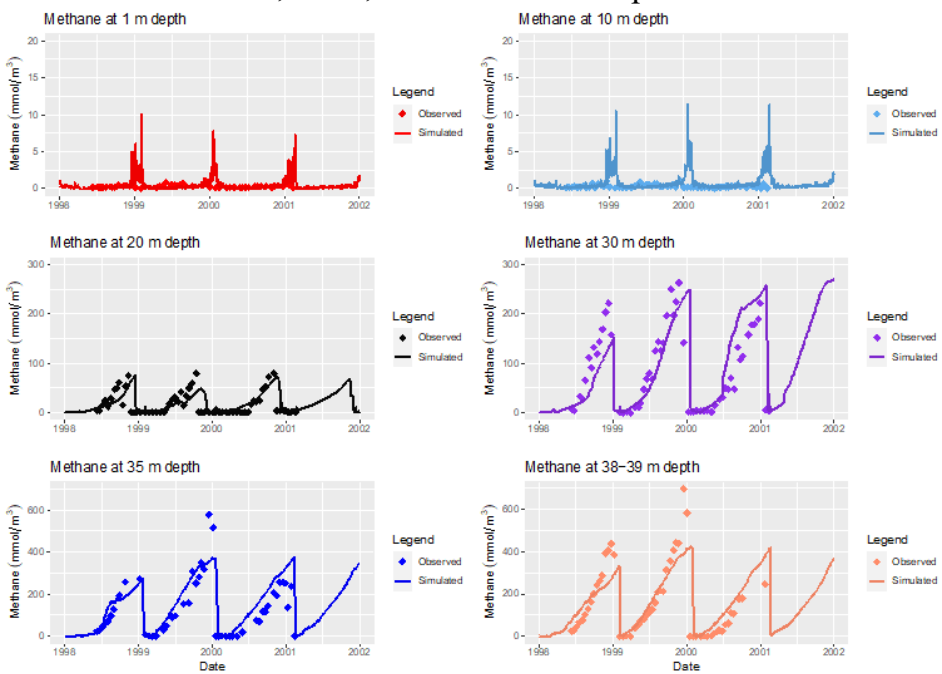

Figure 4. The observed vs. simulated dissolved methane concentrations at $1 \mathrm{~m}, 10 \mathrm{~m}, 20 \mathrm{~m}, 30 \mathrm{~m}, 35 \mathrm{~m}$ and 38-39 m depths. 


\subsection{Sources and sinks of dissolved methane and methane bubbles}

The sources and sinks for dissolved methane in the water column are presented in Figure 5. The dissolution of bubbles and diffusion show great seasonal variations. In Lake Kinneret, the dissolution of bubbles is a more significant source of dissolved methane than diffusion. This was expected, as in Lake Kinneret ebullition is of greater magnitude than diffusion. Aerobic oxidation in the water column is an episodic process, with the highest oxidation rates occurring during mixing. Gas exchange at the water air interface is a highly episodic process and the greatest emissions occur during holomixis each year. The magnitude of methane emissions during holomixis might have been overestimated due to the higher surface methane concentrations simulated by the model.

The sources and sinks of ebullition in the water column are shown in Figure 6. The great seasonality of ebullition is evident and is due to its temperature sensitivity. The smaller spikes on the graph possibly reflect the changes in the ebullitive flux in response to lake level changes. It seems that the model doesn't appropriately capture the episodic nature of ebullition.

\section{DISCUSSION}

\subsection{Model performance}

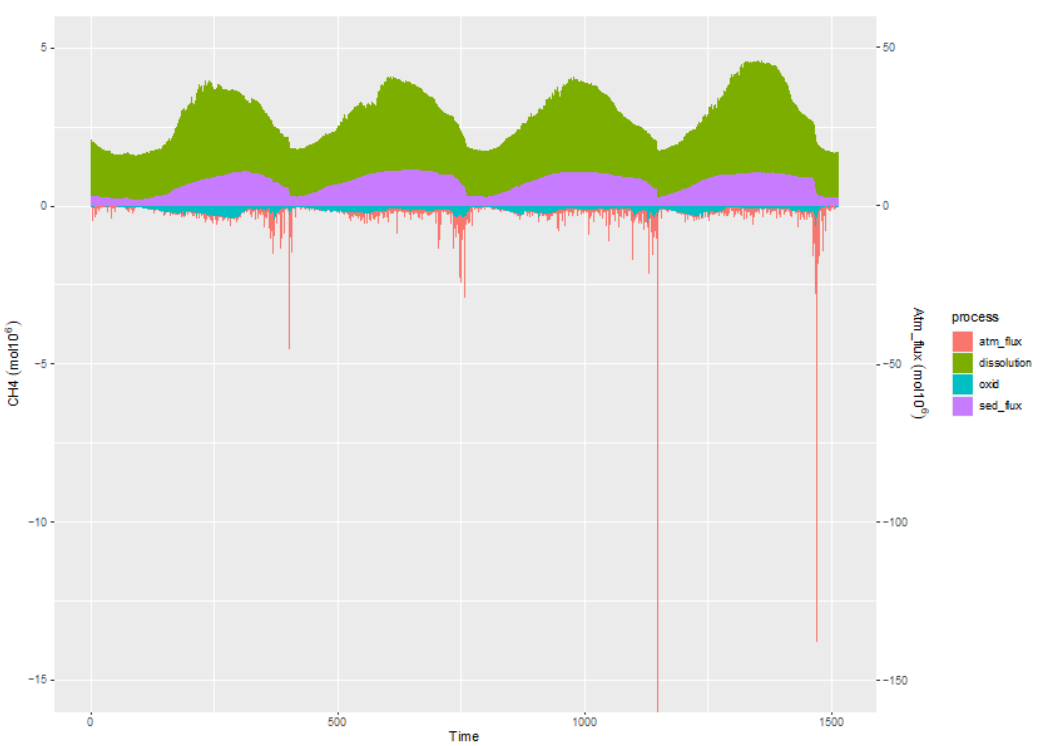

Figure 5. The sources and sinks of dissolved methane (stacked) in Lake

Kinneret, including dissolution of bubbles ("dissolution"), sediment diffusive flux ("sed_flux"), aerobic oxidation ("oxid") and gas exchange at the water-air interface. ("atm_flux").

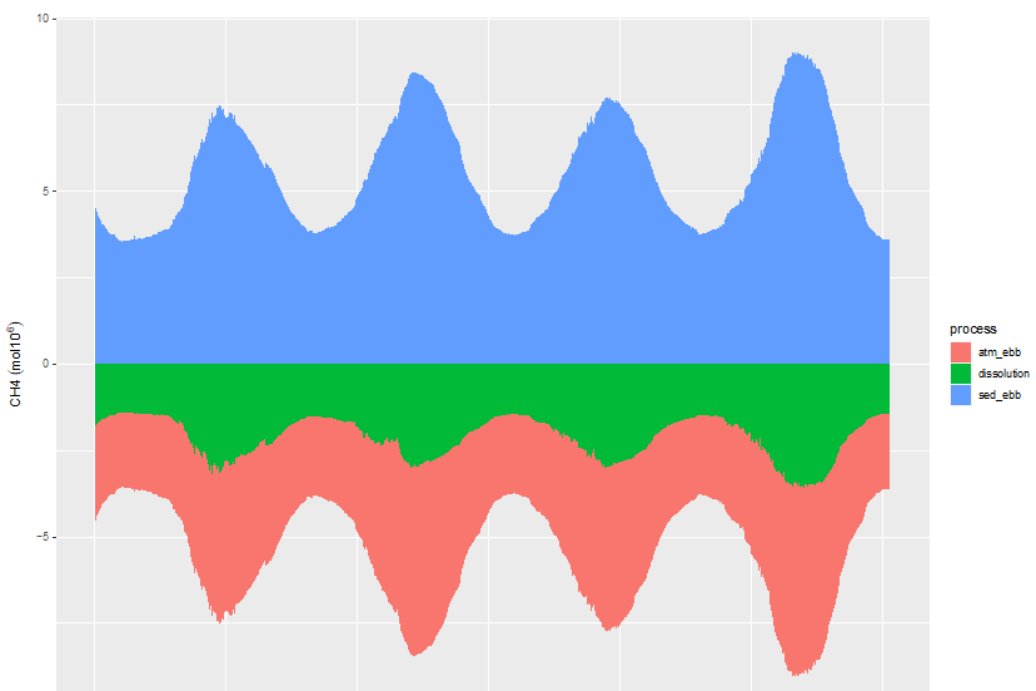

Figure 6. The sources and sinks of ebullition (stacked) in Lake Kinneret including the sediment bubble flux ("sed_ebb"), the dissolution of bubbles ("dissolution") and the atmospheric ebullition flux ("atm_ebb").

In this study, a one-dimensional hydrodynamic model (GLM) coupled with a biogeochemical model (AED) was used to simulate the methane sources and sinks in Lake Kinneret, including a new algorithm to simulate ebullition. The new ebullition model has successfully simulated the sediment ebullitive flux, the atmospheric ebullitive flux and the dissolution of bubbles in the water column. However, it is a simplified version of the single bubble model (McGinnis et al. 2006). The seasonal accumulation of dissolved methane in the hypolimnion was captured well and the results were comparable to those of Schmid et al. (2017). Interestingly, the small lag in the development of anoxic conditions in the hypolimnion did not cause a delay in the accumulation of dissolved methane at the bottom of the lake. The small over and underestimations of hypolimnetic methane concentration could be due to slightly underestimated hypolimnion temperatures or other factors not included in the model. The epilimnion methane concentrations were overestimated during mixing resulting in more rapid gas exchange in the water-air interface, enhancing emissions. The model was calibrated by comparing the simulated state variables (i.e. temperature, DO and dissolved methane 
concentrations) to observations. However, there were no observations available for the calibration and validation of the ebullition model to directly evaluate its performance. To shed light on any structural error in the ebullition model, observed ebullitive flux rate data are needed.

\subsection{Ebullition model}

The ebullition model captures the great seasonality of ebullition well which is due to its temperature sensitivity (DelSontro et al. 2010). However, the episodic pattern of ebullition reported in the literature (McGinnis et al. 2006), was not captured by the model. According to the current knowledge of ebullition, it generally occurs when the methane production rate exceeds the rate of diffusion, whilst decreasing hydrostatic pressure has been found to enhance the ebullitive flux. Simulating this behaviour requires resolving methane build up in the sediments based on trophic status and ebullitive flux based on hydrodynamics, instead of site-specific water level equation. This could be achieved by building an algorithm based on temperature, sediment organic matter content and various hydrodynamic thresholds, which would enable the application of the model to a wide range of lake systems. Currently, uncertainty analysis of the model is underway to demonstrate the relative sources of uncertainty that contribute to atmospheric methane emission estimates.

\section{CONCLUSION}

Process-based models have the ability to account for the variability in lake characteristics and capture the interannual and within system variations in methane emissions. Unlike other process descriptions that are suitable for generalisation across lakes, there is still a niche for general methane models that can be applied to a diversity of lake systems.

\section{REFERENCES}

Bastviken, D., Cole, J., Pace, M., Tranvik, L., 2004. Methane emissions from lakes: Dependence of lake characteristics, two regional assessments, and a global estimate, Global biogeochemical cycles, 18.

Borrel, G., Jézéquel, D., Biderre-Petit, C., Morel-Desrosiers, N., Morel, J.-P., Peyret, P., Fonty, G., Lehours, A.-C., 2011. Production and consumption of methane in freshwater lake ecosystems, Research in microbiology, 162, 832-847.

DelSontro, T., McGinnis, D. F., Sobek, S., Ostrovsky, I., and Wehrli, B., 2010. Extreme Methane Emissions from a Swiss Hydropower Reservoir: Contribution from Bubbling Sediments, Environmental science \& technology, 44, 2419-2425.

Gal, G., Imberger, J., Zohary, T., Antenucci, J., Anis, A., Rosenberg, T., 2003. Simulating the thermal dynamics of Lake Kinneret, Ecological modelling, 162, 69-86.

Hipsey, M., Bruce, L., and Hamilton, D., 2013. Aquatic Ecodynamics (AED) Model Library Science Manual, The University of Western Australia Technical Manual, Perth, Australia, 34.

Hipsey, M. R., Bruce, L. C., Boon, C., Busch, B., Carey, C. C., Hamilton, D. P., Hanson, P. C., Read, J. S., de Sousa, E., Weber, M., Winslow, L. A., 2019. A General Lake Model (GLM 3.0) for linking with highfrequency sensor data from the Global Lake Ecological Observatory Network (GLEON), Geoscientific model development, 12, 473-523.

McGinnis, D. F., Greinert, J., Artemov, Y., Beaubien, S. E., Wüest, A., 2006. Fate of rising methane bubbles in stratified waters: How much methane reaches the atmosphere?, Journal of Geophysical Research - Oceans, 111.

Ostrovsky, I., Rimmer, A., Yacobi, Y. Z., Nishri, A., Sukenik, A., Hadas, O., Zohary, T.,2013. Long-term changes in the Lake Kinneret ecosystem: the effects of climate change and anthropogenic factors, Climatic change and global warming of inland waters: impacts and mitigation for ecosystems and societies, 271-293.

Sanches, L. F., Guenet, B., Marinho, C. C., Barros, N., de Assis Esteves, F., 2019. Global regulation of methane emission from natural lakes, Scientific reports, 9, 255-255.

Schmid, M., Ostrovsky, I., McGinnis, D. F., 2017. Role of gas ebullition in the methane budget of a deep subtropical lake: What can we learn from process-based modeling?, Limnology and oceanography, 62, 26742698.

Stepanenko, V., Mammarella, I., Ojala, A., Miettinen, H., Lykosov, V., Vesala, T., 2016. LAKE 2.0: a model for temperature, methane, carbon dioxide and oxygen dynamics in lakes, Geoscientific model development, 9, 1977-2006.

Wanninkhof, R., 1992. Relationship between wind speed and gas exchange over the ocean, Journal of Geophysical Research, 97, 7373-7382. 